\title{
Reassessment of hydrogen tolerance in Caldicellulosiruptor saccharolyticus
}

\author{
Karin Willquist, Sudhanshu S Pawar ${ }^{*}$ and Ed WJ Van Niel
}

\begin{abstract}
Background: Caldicellulosiruptor saccharolyticus has the ability to produce hydrogen $\left(\mathrm{H}_{2}\right)$ at high yields from a wide spectrum of carbon sources, and has therefore gained industrial interest. For a cost-effective biohydrogen process, the ability of an organism to tolerate high partial pressures of $\mathrm{H}_{2}\left(P_{\mathrm{H}_{2}}\right)$ is a critical aspect to eliminate the need for continuous stripping of the produced $\mathrm{H}_{2}$ from the bioreactor.

Results: Herein, we demonstrate that, under given conditions, growth and $\mathrm{H}_{2}$ production in $\mathrm{C}$. saccharolyticus can be sustained at $P_{\mathrm{H} 2}$ up to $67 \mathrm{kPa}$ in a chemostat. At this $P_{\mathrm{H} 2}, 38 \%$ and $16 \%$ of the pyruvate flux was redirected to lactate and ethanol, respectively, to maintain a relatively low cytosolic NADH/NAD ratio $(0.12 \mathrm{~mol} / \mathrm{mol})$. To investigate the effect of the redox ratio on the glycolytic flux, a kinetic model describing the activity of the key glycolytic enzyme, glyceraldehyde-3-phosphate dehydrogenase (GAPDH), was developed. Indeed, at NADH/NAD ratios of $0.12 \mathrm{~mol} / \mathrm{mol}(\mathrm{Ki}$ of $\mathrm{NADH}=0.03 \pm 0.01 \mathrm{mM}$ ) GAPDH activity was inhibited by only $50 \%$ allowing still a high glycolytic flux $(3.2 \pm 0.4 \mathrm{mM} / \mathrm{h}$ ). Even at high NADH/NAD ratios up to $1 \mathrm{~mol} / \mathrm{mol}$ the enzyme was not completely inhibited. During batch cultivations, hydrogen tolerance of $C$. saccharolyticus was dependent on the growth phase of the organism as well as the carbon and energy source used. The obtained results were analyzed, based on thermodynamic and enzyme kinetic considerations, to gain insight in the mechanism underlying the unique ability of $\mathrm{C}$. saccharolyticus to grow and produce $\mathrm{H}_{2}$ under relatively high $P_{\mathrm{H} 2}$.

Conclusion: $C$. saccharolyticus is able to grow and produce hydrogen at high $P_{\mathrm{H} 2}$, hence eliminating the need of gas sparging in its cultures. Under this condition, it has a unique ability to fine tune its metabolism by maintaining the glycolytic flux through regulating GAPDH activity and redistribution of pyruvate flux. Concerning the later, xylose-rich feedstock should be preferred over the sucrose-rich one for better $\mathrm{H}_{2}$ yield.
\end{abstract}

Keywords: Caldicellulosiruptor saccharolyticus, biohydrogen production, hydrogen tolerance, enzyme levels, glyceraldehyde-3-phosphate dehydrogenase kinetics, redox ratio

\section{Background}

In the continuous quest for an economically competitive biohydrogen production plant, it is important to obtain as high $\mathrm{H}_{2}$ yields as possible [1]. The $\mathrm{H}_{2}$ yields reported in literature for dark fermentation with various mesophilic microorganisms are usually in the range of $1-2$ moles per mole of hexose [2-5], whereas a maximum empirical yield can be gained of $4 \mathrm{~mol} \mathrm{H}_{2} / \mathrm{mol}$ hexose [6]. One successful strategy to maximize $\mathrm{H}_{2}$ yields is to carry out the fermentation with (hyper)thermophiles at elevated temperatures. This makes the $\mathrm{H}_{2}$-generation

\footnotetext{
* Correspondence: Sudhanshu.Pawar@tmb.Ith.se

Department of Applied Microbiology, Lund University, P.O. Box 124, SE-221
} 00 Lund, Sweden reactions more energetically favourable [7] and has, therefore, a positive impact on $\mathrm{H}_{2}$ yields [5,8]. Indeed, the highest $\mathrm{H}_{2}$ yields reported to date, approaching the theoretical maximum, were obtained with (hyper)thermophiles [9-11].

Since $\mathrm{H}_{2}$ is known to have an inhibitory effect on growth and its own production in a variety of microorganisms, including (hyper)thermophiles [5,8], maximizing fermentative $\mathrm{H}_{2}$ yield is made possible by keeping the $P_{\mathrm{H} 2}$ in the fermentation vessel sufficiently low. Normally, this is ensured by continuous stripping of the $\mathrm{H}_{2}$ from the production broth using an inert gas, such as $\mathrm{N}_{2}$ or $\mathrm{He}$ [12]. However, using an inert gas requires a subsequent energy-demanding gas-upgrading step [13]. Instead, $\mathrm{CO}_{2}$ might offer an economic alternative [14] 
as it is a by-product of the fermentation process and can be more readily separated from $\mathrm{H}_{2}$ [13]. However, stripping with $\mathrm{CO}_{2}$ increases the osmolality of the fermentation broth, ultimately reducing the growth of the $\mathrm{H}_{2}$ producing organism[15]. To avoid stripping, high $\mathrm{H}_{2}$ yields have simply to be obtained at high $P_{\mathrm{H} 2}$.

Caldicellulosiruptor saccharolyticus is a strict anaerobic, extreme thermophilic bacterium that is able to produce nearly stoichiometric amounts of $\mathrm{H}_{2}$ from glucose [9] and sucrose [16]. In addition, C. saccharolyticus has the unique ability to co-metabolize a wide spectrum of carbohydrates including both pentoses and hexoses $[17,18]$, and to break down complex hemi-cellulosic materials as well as other complex polysaccharides [19-22]. The genome of this organism has been recently sequenced [17] facilitating improved discernments of its metabolic network.

High $\mathrm{H}_{2}$ yields can only be achieved when acetate is the main metabolic by-product, since the formation of more reduced products, such as lactate and ethanol, drains electrons from $\mathrm{H}_{2}$ production. In this work, we evaluated the influence of elevated $P_{\mathrm{H} 2}$ on growth, the extent of lactate formation and accordingly $\mathrm{H}_{2}$ yields, by C. saccharolyticus in batch as well as carbon-limited continuous cultures, with glucose as the main carbon and energy source. The effect of $P_{\mathrm{H} 2}$ on $C$. saccharolyticus metabolism on pentoses (xylose) was also evaluated in batch cultures and was compared with previous results on disaccharides (sucrose; [23]). We demonstrate that, depending on the growth conditions, the organism can grow and produce $\mathrm{H}_{2}$ at $P_{\mathrm{H} 2}$ up to $67 \mathrm{kPa}$. The activity levels of three redox-related catabolic enzymes were compared in the presence and the absence of $\mathrm{N}_{2}$ sparging and correlated with product distribution under each condition. In addition, a kinetic model was developed to examine the influence of the changes in the intracellular levels of NADH on the activity of a key glycolytic enzyme, glyceraldehyde-3-phosphate dehydrogenase $(\mathrm{GAPDH})$, and is compared with other related organisms. The obtained results are analyzed, based on thermodynamic considerations, to understand the mechanism underlying the unique ability of C. saccharolyticus to grow and produce $\mathrm{H}_{2}$ under relatively high $P_{\mathrm{H} 2}$.

\section{Materials and methods}

\section{Microorganism and culture medium}

C. saccharolyticus DSM 8903 was purchased from the Deutsche Sammlung von Mikroorganismen und Zellkulturen (Braunschweig, Germany). A modified DSM 640 medium [15] was used for all cultivations throughout this work. Routine subcultures and inoculum development were conducted in 250-mL serum bottles containing 50-mL of medium. Anoxic solutions of different carbon sources were autoclaved separately and added to the sterile medium at the required concentration.

\section{Fermentation setup}

Cultures were grown in a jacketed, 3-L bioreactor equipped with an ADI 1025 Bio-Console and an ADI 1010 Bio-Controller (Applikon, Schiedam, The Netherlands) at a working volume of $1 \mathrm{~L}$, either in batch or continuous mode. The $\mathrm{pH}$ was maintained at $6.5 \pm 0.1$ at $70^{\circ} \mathrm{C}$ by automatic titration with $4 \mathrm{M} \mathrm{NaOH}$. The temperature was thermostatically kept at $70 \pm 1^{\circ} \mathrm{C}$ and the stirring rate was set to $250 \mathrm{rpm}$. A condenser with $5^{\circ} \mathrm{C}$ cooling water was fitted to the bioreactor's headplate. Prior to inoculation, the medium was sparged with $\mathrm{N}_{2}$ and supplemented with an anoxic solution of cysteine- $\mathrm{HCl}$ at a final concentration of $1 \mathrm{~g} \mathrm{~L}^{-1}$ to render the medium completely anaerobic. For continuous cultivations, the bioreactor was started to be fed with fresh medium at the end of the logarithmic growth phase of the culture, having an identical composition to the batch start-up medium, except for cysteine- $\mathrm{HCl}$ (final concentration of $0.25 \mathrm{~g} / \mathrm{L}$ in medium bottle) at the required dilution rate $(D)$. Steady states were assessed after at least 5 volume changes based on the criteria of constant $\mathrm{H}_{2}$ and $\mathrm{CO}_{2}$ production rates and constant biomass concentration. Glucose was used as a primary substrate in all batch and continuous experiments at an initial concentration of $5 \mathrm{~g} / \mathrm{L}$, if not stated otherwise.

Three different experimental designs were applied: continuous flushing with $100 \mathrm{~mL} \mathrm{m^{-1 }} \mathrm{N}_{2}$ for continuous removal of produced $\mathrm{H}_{2}$ (Case I); no gas sparging, with the bioreactor's gas outlet open leading to higher concentrations of $\mathrm{H}_{2}$ in the headspace at 1 bar (Case II); no gas sparging, with the bioreactor's gas outlet closed allowing $\mathrm{H}_{2}$ to accumulate and increasing the total pressure in the bioreactor (Case III). Gas samples from the headspace for $\mathrm{H}_{2}$ and $\mathrm{CO}_{2}$ determination and culture samples for monitoring growth, substrate consumption and product formation were regularly withdrawn during fermentation. At steady states, samples were taken for determining the NADH/NAD ratio and cell dry weight (CDW) and anaerobic culture samples for enzyme activity measurements as described previously [24]. Continuous cultivations were performed at the dilution rates of $0.05 \mathrm{~h}^{-1}$ and $0.15 \mathrm{~h}^{-1}$ in duplicate under both, 'Case $I$ and 'Case $I I$ ', conditions.

\section{Analytical methods}

Headspace samples were analyzed for $\mathrm{CO}_{2}$ and $\mathrm{H}_{2}$ by gas chromatography, using a dual channel Micro-GC (CP-4900; Varian, Micro gas chromatography, Middelburg, The Netherlands), as previously described [11]. The results were analyzed with a Galaxie Chromatography Workstation (v.1.9.3.2). The optical density of the 
culture was measured at $620 \mathrm{~nm}\left(\mathrm{OD}_{620}\right)$ using a U1100 spectrophotometer (Hitachi, Tokyo, Japan). CDW was determined by filtration as previously described [24]. Glucose, acetate, lactate, succinate and ethanol were analyzed by HPLC (Waters, Milford, MA, USA) on an Aminex HPX-87H ion exchange column (Bio-Rad, Hercules, USA) at $45^{\circ} \mathrm{C}$, with $5 \mathrm{mM} \mathrm{H}_{2} \mathrm{SO}_{4}(0.6 \mathrm{ml} \mathrm{min}$ $\left.{ }^{1}\right)$ as the mobile phase. The column was equipped with a refractive index detector (RID-6A; Shimadzu, Kyoto, Japan).

\section{Preparation of cell extracts}

Cell extracts (CE) were prepared anaerobically in duplicates using cells harvested from continuous cultures. All cell manipulations were carried out in an anaerobic glove box (Plas Labs Inc., MI, USA) with a $\mathrm{N}_{2} / \mathrm{H}_{2} / \mathrm{CO}_{2}$ atmosphere $(85 / 10 / 5 \mathrm{v} / \mathrm{v})$. Cell suspensions were centrifuged outside the glove box for $5 \mathrm{~min}$ at 5,000 $\times g$ and $4^{\circ} \mathrm{C}$, after the addition of sodium dithionite at a final concentration of $5.2 \mathrm{mg} \mathrm{L}^{-1}$ to ensure complete anaerobiosis. The cell pellets were resuspended in a reaction buffer $(0.1 \mathrm{M}$ Tris- $\mathrm{HCl}$ containing $40 \mathrm{mM} \mathrm{NaCl}$ and 5 $\mathrm{mM} \mathrm{MgCl}_{2} ; \mathrm{pH}$ 7.2) [24] Cells were mixed with an equal volume of $0.1 \mathrm{~mm}$ silica beads and disrupted in a Mini-Beadbeater (BioSpec Products Inc., OK, USA) in 3 cycles of $20 \mathrm{~s}$ beating and $60 \mathrm{~s}$ cooling. Cell debris was removed by $5 \mathrm{~min}$ centrifugation at $12,000 \times g$ (Minispin, Eppendorf, Hamburg, Germany) and the resulting CE was either used directly or stored under anaerobic conditions at $-20^{\circ} \mathrm{C}$ until use. For determination of GAPDH kinetics, the CE was freed from compounds with a $\mathrm{M}_{\mathrm{W}}$ below $5 \mathrm{kDa}$ using a PD10 column (SigmaAldrich), as previously described [24].

\section{Enzyme assays}

All enzyme activity measurements were carried out as described previously [24], with the modification that $5.35 \mathrm{mM}$ GAP was used in the assay for GAPDH activity. All assays were carried out in at least three technical replicates in the linear protein concentration range. In addition, the influence of the metabolites ATP, ADP and PPi on GAPDH activity in the concentration range of 1-10 mM was evaluated. The $K_{0.5}$ for the substrates GAP and $\mathrm{NAD}^{+}$were determined by using seven different GAP concentrations and varying the $\mathrm{NAD}^{+}$concentration. The $K i$ for NADH was determined by using four different $\mathrm{NAD}^{+}$concentrations and varying $\mathrm{NADH}$ concentration.

Background reactions for the assays were determined by replacing the substrate with the reaction buffer. One unit of enzyme activity (IU) is defined as the amount of enzyme that catalyzes the conversion of $1 \mu \mathrm{mol}$ of substrate per min. Specific activities are expressed as IU $(\mathrm{mg} \text { protein })^{-1}$. Protein concentration in the CE was determined according to Bradford (1976), with bovine serum albumin as a standard.

\section{$\mathrm{NAD}(\mathrm{H})$ assay}

The intracellular concentrations of NADH and NAD were determined by a cyclic assay as described earlier $[25,24]$, with the exception of using phenazine ethosulfate (PES) instead of phenazine methosulfate (PMS), as PES is chemically more stable than PMS [25].

\section{Measurement of ATP and PPi}

Samples were collected in screw-cap microcentrifuge tubes containing ice-cold chloroform and immediately frozen into liquid nitrogen. Samples were stored at $-80^{\circ}$ $\mathrm{C}$ until further analysis. During the sample preparation cells were not separated from the medium to avoid the loss of ATP and/or PPi due to possible leakage during centrifugation, as previously observed by Bielen et al [26]. Moreover, assays were also done to estimate the levels of ATP and PPi in the growth medium. ATP and PPi were extracted from the cells by using the cell lysis buffer as described in the protocol provided with the ATP Bioluminescence assay kit HSII (Roche Molecular Biochemicals). ATP was measured using the ATP Bioluminescence assay kit HSII (Roche Molecular Biochemicals) containing luciferin/luciferase reagent, according to the protocol provided with the kit, in a tube-reading 1250 Luminometer (LKB-Wallac, Turku, Finland).

Samples for PPi measurement were treated with ATPsulfurylase (Sigma-Aldrich, Germany) in the presence of excess Adenosine-5'-phosphosulfate to produce ATP from PPi [27] and the overall ATP was measured with the Bioluminescence assay kit HSII (Roche Molecular Biochemicals). Since significant amounts of ATP were present in the samples, the assay was started with the measurement of ATP, to convert most of the ATP into PPi and immediately ATP sulfurylase was added to convert overall PPi into ATP, which was subsequently measured. The background signal, less than $15 \%$ of the total signal in all measurements, was subtracted from the total signal to estimate the net PPi concentration. Intracellular levels of ATP and PPi were calculated as previously described [26].

\section{Calculations}

$\mathrm{H}_{2}$ productivity $\left(\mathrm{mM} \mathrm{h}^{-1}\right)$ and cumulative $\mathrm{H}_{2}$ formation ( $\mathrm{CHF}, \mathrm{mM})$ were calculated in two different ways depending on the experimental design. All calculations were based on the ideal gas law using $\mathrm{H}_{2}$ and $\mathrm{CO}_{2}$ concentration in the headspace. For Case I (sparging with $\mathrm{N}_{2}$ ) the calculations were based on the flow rate of the influent $\mathrm{N}_{2}$ gas and the percentages of $\mathrm{H}_{2}$ and $\mathrm{CO}_{2}$ in the effluent gas, as no other gases were detected, whereas for Case II (no sparging) the flow rate of the 
effluent gas was measured by the water displacement method with $\mathrm{CO}_{2}$-saturated water to avoid any further $\mathrm{CO}_{2}$ to dissolve. It was assumed that $\mathrm{CO}_{2}$ in the effluent gas did not dissolve in the $\mathrm{CO}_{2}$-saturated water; therefore the actual dissolved $\mathrm{CO}_{2}$ concentration was not determined. $\mathrm{CO}_{2}$-saturated water was prepared by stripping the boiling water with $100 \% \mathrm{CO}_{2}$, cooling it down simultaneously and was kept cold throughout the experiment. At the steady state, the flow rate of the effluent gas was determined by measuring the volume of the effluent gas collected between two time points. Thus, $\mathrm{H}_{2}$ productivity and CHF were calculated based on hydrogen concentration in the effluent gas and the flow rate of the effluent gas.

The intracellular specific productivities $\left(\mathrm{mmol} \cdot \mathrm{g}^{-1} \cdot \mathrm{h}^{-1}\right)$, i.e. $q_{\mathrm{NADH}}$ produced, $q_{\mathrm{NADH}}$ used, $q_{\mathrm{NADH}}$ available and $q_{\text {pyruvate, }}$ were estimated as described previously [28].

The biomass yield per mol of ATP ( $Y_{\text {x/ATP }}$ g. mol $\left.^{-1}\right)$ was calculated based on the equation previously described [15]:

$$
Y_{\mathrm{x} / \mathrm{ATB}}=\frac{[\text { biomass }]}{1.5 \times[\text { acetate }]+0.5 \times[\text { lactate }]+0.5 \times[\text { ethanol }]}
$$

The dissolved $\mathrm{H}_{2}$ concentration $\left(\mathrm{H}_{2, \text { aq }}\right)$ in equilibrium was estimated according to Henry's law:

$$
\mathrm{H}_{2, \mathrm{aq}}=P_{\mathrm{H} 2} \times K_{\mathrm{H}}
$$

where $K_{\mathrm{H}}$ is Henry's constant ( $\mathrm{mM} / \mathrm{bar}$ ) and is dependent on the temperature according to:

$$
\ln \frac{K_{2}}{K_{1}}=\frac{\Delta H^{0}}{R} *\left[\frac{1}{T_{1}}-\frac{1}{T_{2}}\right]
$$

where $K_{1}$ is $K_{\mathrm{H}}$ at $T_{1}=298 \mathrm{~K}\left(0.78 \mathrm{mM} / \mathrm{bar}\right.$, [29]), $K_{2}$ is the calculated $K_{\mathrm{H}}$ at $T_{2}=343 \mathrm{~K}(0.52 \mathrm{mM} / \mathrm{bar}), \Delta \mathrm{H}$ $(\mathrm{J} / \mathrm{mol})$ is the enthalphy at standard conditions and $\mathrm{R}$ $(8.314 \mathrm{~J} / \mathrm{mol} / \mathrm{K})$ is the gas constant.

\subsection{GAPDH model, data fitting and statistical analysis}

The affinity constants for the substrates GAP and NAD ${ }^{+}$ was determined by fitting the Michaelis-Menten type kinetic equation to the obtained data [30]:

$$
v=V_{\max } * \frac{\left[\mathrm{NAD}^{+}\right] *[\mathrm{GAP}]}{K_{\mathrm{GAP}} *\left[\mathrm{NAD}^{+}\right]+K_{\mathrm{NAD}} *[\mathrm{GAP}]+[\mathrm{GAP}] *\left[\mathrm{NAD}^{+}\right]+\alpha * K_{\mathrm{GAP}}}
$$

where $V$ is the reaction rate, $V_{\max }$ is the maximum rate of the reaction, $K_{G A P}$ and $K_{N A D}$ are the affinity constants for GAP and $\mathrm{NAD}^{+}$, respectively, and $\alpha$ is a constant representing any interaction between NAD and GAP binding to the enzyme. However, from analysis of our data $\alpha$ was not significantly higher than zero and was, therefore, the term " $\alpha \times K_{G A P}$ " was excluded from the equation.
The inhibition kinetics of NADH was determined by using four different $\mathrm{NAD}^{+}$concentrations and varying NADH concentrations. The type of inhibition kinetics was visualized by fitting equations for i) sigmoidal competitive inhibition, ii) uncompetitive inhibition iii) mixed inhibition, or iv) linear competitive inhibition

$$
v=\frac{V_{\max } *\left(\mathrm{NAD}^{+}\right) *(\mathrm{GAP})}{\left[K_{\mathrm{GAP}}+(\mathrm{GAP})\right] *\left[K_{\mathrm{NAD}} *\left(1+\left(\frac{\mathrm{NADH}}{K_{\mathrm{NADH}}}\right)\right)+\left(\mathrm{NAD}^{+}\right)\right]}
$$

where $K_{N A D H}$ is an inhibition constant, to the experimental data [30].

Data obtained from the inhibition kinetics of NADH was also used to study the effect of NADH/NAD (redox ratio) on GAPDH activity by assuming redox ratio as a substrate. Hill type kinetic equation was fitted to the data [30]:

$$
v=\frac{V_{\max }}{1+\left(\frac{K_{R}}{S}\right)^{h}}
$$

where $\mathrm{S}$ is the redox ratio, $K_{R}$ is an affinity constant and $h$ is the Hill coefficient of cooperatively.

Parameter estimation (viz. $V_{\max }, \alpha, K_{G A P}, K_{N A D}$, $K_{N A D H}, K_{R}$ and $h$ ) was based on non-linear regression using the Surface Fitting Tool (sftool) or curve fitting tool (cftool) in MATLAB (R2009a), which also provides a statistical analysis. Model discrimination was based on the goodness of fit, which was evaluated by the $95 \%$ confidence bounds for the fitted parameters and by the square of the multiple correlation coefficients $\left(R^{2}\right)$.

Estimations on LDH activity was based on previously published model of LDH regulation in C. saccharolyticus [24].

\section{Results and discussion}

3.1 Effect of $\mathrm{P}_{\mathrm{H} 2}$ on growth and lactate formation in batch cultures

C. saccharolyticus was cultivated in $\mathrm{pH}$-controlled batch mode, with and without $\mathrm{N}_{2}$ sparging. The $P_{\mathrm{H} 2}$ peaked at $6.3 \mathrm{kPa}$ with sparging and $67 \mathrm{kPa}$ without sparging the culture, which allowed analyzing the influence of the $P_{\mathrm{H} 2}$ on growth and product formation. In both cases, the organism grew at a similar rate until a critical $P_{\mathrm{H} 2}$ of $11 \mathrm{kPa}$ was reached in the gas phase of the nonsparged fermentor, at which the growth rate decreased by $24 \%$ (Figure $1 \mathrm{~A}$ ). Moreover, when the $P_{\mathrm{H} 2}$ reached $30 \mathrm{kPa}$ (after $14 \mathrm{~h}$ of growth; Figure 1A) growth became linear. In contrast, the sparged culture grew exponentially until glucose was almost depleted after 16 hours of incubation (Figure 1A and 1B). Inhibition of growth is probably a result of both high dissolved hydrogen 

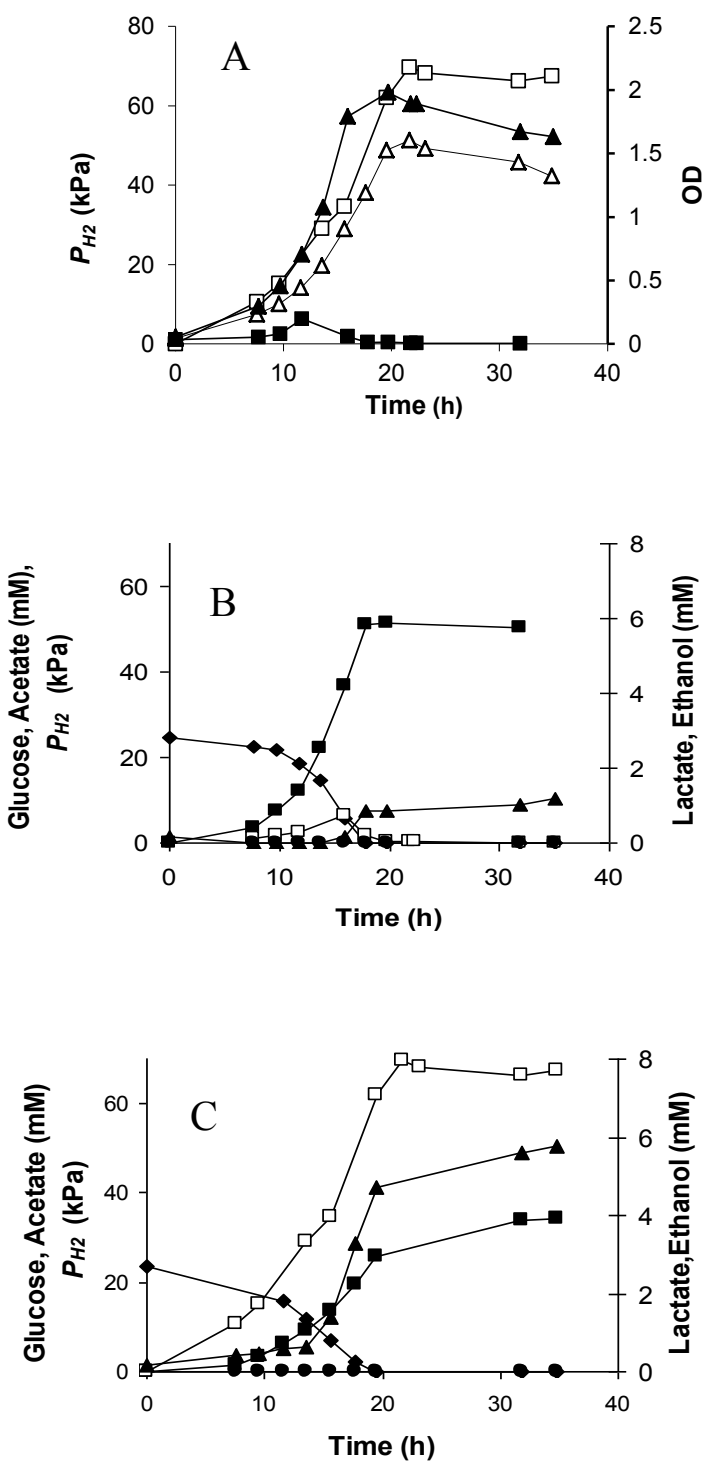

Figure 1 Growth and product formation by C. saccharolyticus in $\mathrm{pH}$-controlled batch fermentations with and without $\mathrm{N}_{2}$ sparging. (A) with sparging (filled symbols) and without sparging (open symbols) growth $(\mathbf{\Lambda}, \Delta)$ and $P_{\mathrm{H}_{2}}(\boldsymbol{\bullet}$, 口). Product formation in the presence (B) and absence of $\mathrm{N}_{2}$ sparging $(\mathrm{C})$ glucose $(\boldsymbol{})$, acetate $(\boldsymbol{\bullet})$, lactate $(\boldsymbol{\bullet})$, ethanol $(\bullet)$ and $P_{\mathrm{H}_{2}}(\square)$. Note: Different scales are used on primary and secondary vertical axes.

concentration and high osmolarity due to high dissolved $\mathrm{CO}_{2}$ concentrations in the non-stripped reactor [31].

Consistent with previous findings [24], acetate and $\mathrm{H}_{2}$ were the main metabolic end products during exponential growth when the culture was sparged with $\mathrm{N}_{2}$ (Figure 1B). Lactate formation was in this case initiated in the transition to stationary phase at a low $P_{\mathrm{H} 2}(6.3 \mathrm{kPa})$.

Moreover, although some lactate was produced during early growth in the absence of sparging, the lactate productivity accelerated when the growth became linear after 14 hours of cultivation (Figure 1C). At this point, the $P_{\mathrm{H} 2}$ was $30 \mathrm{kPa}$, thus about 2-fold higher than the previously quoted critical $P_{\mathrm{H} 2}$ for lactate formation (10$20 \mathrm{kPa}$; [23]). The $\mathrm{H}_{2}$ productivity was not determined due to technical difficulties in accurate determination of instable increasing productivities with water displacement techniques. These results indicated that in batch cultivations, the cells can withstand higher $P_{\mathrm{H} 2}$ maintaining an exponential growth profile until lactate is started to be formed, accompanied with linear growth.

The increased $P_{\mathrm{H} 2}$ clearly influenced the overall lactate yield, as the final lactate concentration was 5 -fold higher when the culture was not sparged with $\mathrm{N}_{2}$ (Figure 1B and $1 C$ ). The acetate/lactate ratio was 43 and 6 for the sparged and the non-sparged conditions, respectively. Ethanol, which acts as an alternative electron sink for $C$. saccharolyticus, was present in negligible quantities, irrespective of the $P_{\mathrm{H} 2}$ (Figure $1 \mathrm{~B}, \mathrm{C}$ ).

This behaviour is consistent with the outcome of another study on metabolic shifts in C. saccharolyticus [31], which demonstrated that a combination of the osmotic pressure and the dissolved $\mathrm{H}_{2}$ concentration determines the metabolic shift to lactate production. The key players behind this are the intracellular energy carriers that influence the lactate dehydrogenase (LDH) [24]. The kinetics of LDH demonstrated that the anabolic byproduct and energy carrier, PPi, plays a central role in the allosteric regulation of this catabolic enzyme by acting as a strong competitive inhibitor $(\mathrm{Ki}=1.7$ $\mathrm{mM})$, therefore antagonizing the stimulating effect of elevated NADH/NAD ratios [24]. The PPi levels in $C$. saccharolyticus are correlated to the growth rate, as the PPi concentration is highest $(4 \pm 2 \mathrm{mM})$ during exponential growth, and decreased seven folds during the transition to the stationary phase [26]. Consequently, at exponential growth, these high PPi levels assure that LDH remains inactive even at higher NADH/NAD (1.2 mol. $\mathrm{mol}^{-1}$ ) ratios. However, when the growth rate decelerates the concomitant decrease in PPi levels enables LDH to become sensitive to an increase in the NADH/NAD ratio [24]. Therefore, lactate is not formed even at high $P_{\mathrm{H} 2}(<30 \mathrm{kPa})$, as long as the cells are able to sustain high PPi levels through maintaining a high growth rate.

\section{Effect of $\mathrm{P}_{\mathrm{H} 2}$ on growth and lactate formation in continuous culture}

Carbon-limited chemostat cultures were used to investigate the effect of $P_{\mathrm{H} 2}$ on $C$. saccharolyticus at a controlled physiological state. In the absence of gas sparging, the $P_{\mathrm{H} 2}$ reached $67 \mathrm{kPa}$ after about 10 volume changes at $D=0.05 \mathrm{~h}^{-1}$ without any washout of the culture indicating that $C$. saccharolyticus can withstand higher $P_{\mathrm{H} 2}$ than was previously reported [23]. A 
noticeable effect of the elevated $P_{\mathrm{H} 2}$ in this case was the redirection of the pyruvate flux, i.e. $38 \%$ and $16 \%$ of the flux at the pyruvate node was directed to lactate and ethanol, respectively, whereas $0.5 \%$ and $4.1 \%$ of corresponding fluxes were observed in sparged cultures at similar dilution rates (Table 1). Interestingly, the overall catabolic rate (qglucose $)$ was not reduced at this high $P_{\mathrm{H} 2}$ (Table 1). However, a steady state could not be attained in the absence of $\mathrm{N}_{2}$ sparging at a higher $D\left(0.15 \mathrm{~h}^{-1}\right)$ and the culture washed out at $P_{\mathrm{H} 2}$ of $67 \mathrm{kPa}$. These results are in line with previous findings of supersaturation of hydrogen around the cell surface at high productivities due to mass transfer limitation [31]. Under the assumption of an equilibrium between dissolved $\left(\mathrm{H}_{2, \text { aq }}\right)$ and gaseous $\mathrm{H}_{2}$, the $\mathrm{H}_{2 \text {,aq }}$ should be $0.24 \mu \mathrm{M}$ at $67 \mathrm{kPa}$ in the headspace and $70^{\circ} \mathrm{C}$ (Eq. 2 and 3), hence well below the critical $\mathrm{H}_{2 \text {,aq }}$ concentration for growth $\left(\mathrm{H}_{2 \text {,aq }}\right.$ crit $=2.2 \mathrm{mM}$; [31]. However, the actual concentration around the cell depends on the ratio of $\mathrm{H}_{2}$ productivity/ $\mathrm{H}_{2}$ mass transfer rate [31]. Therefore, the observation that the cells washed out at high $\mathrm{D}\left(0.15 \mathrm{~h}^{-1}\right)$ but retained at low $\mathrm{D}\left(0.05 \mathrm{~h}^{-1}\right)$ strongly indicates that at a lower growth rate, the $\mathrm{H}_{2}$ productivity is in the same range as compared to the mass transfer rate such that $\mathrm{H}_{2 \text {,aq }}<\mathrm{H}_{2 \text {,aq crit }}$ In contrast, at the higher growth rate, the hydrogen productivity exceeds the mass transfer rate by far, especially under non-sparging conditions, resulting in supersaturation of hydrogen and thus extensive growth inhibition [31].

Under $\mathrm{N}_{2}$-sparging conditions, the dilution rate also had an effect on product distribution. At $D=0.15 \mathrm{~h}^{-1}$, the $\mathrm{H}_{2}$ yield was lower than at $D=0.05 \mathrm{~h}^{-1}(2.9 \pm 0.2$ $\mathrm{mol} / \mathrm{mol}$ glucose and $3.48 \pm 0.09 \mathrm{~mol} \mathrm{H}_{2} / \mathrm{mol}$ glucose, respectively), which agrees with the findings of de Vrije et al [9]. Moreover, only $86 \%$ of pyruvate flux was directed to acetate at $D=0.15 \mathrm{~h}^{-1}$, compared to a $95 \%$ flux at $D=0.05 \mathrm{~h}^{-1}$. In addition, as previously reported [9], more residual glucose was observed at higher $D$ (Table 1).

The biomass yield of $C$. saccharolyticus at low $P_{\mathrm{H} 2}$ is slightly higher than that in Clostridium cellulolyticum [32], but similar to that in Thermoanaerobacter ethanolicus [33], and significantly lower than that in $\mathrm{Cl}$. acetobutylicum [34]. The increase in the energetic biomass yield of $C$. saccharolyticus at the higher $D$ was also observed for $\mathrm{Cl}$. cellulolyticum [32] and T. ethanolicus [33].

\section{Level of key redox-related catabolic enzymes}

The increase in $P_{\mathrm{H} 2}$ appeared to enhance lactate formation in $C$. saccharolyticus (Table 1). Therefore, the activities of different catabolic dehydrogenase enzymes were determined in cells grown in continuous cultures (Table 2 ). The specific activity of GAPDH decreased about $60 \%$ with an increase in the growth rate. On the other hand, the opposite trend was observed in the specific activities of $\mathrm{LDH}$ and $\mathrm{ADH}$. The level of specific LDH activity increased almost eight folds in absence of sparging, which corresponded well with the observed increase in the lactate flux (Table 1, 2). This correlation is comparable to the 2-fold increase in specific LDH activity and lactate flux during the transition to the stationary phase in batch cultures of $C$. saccharolyticus on $10 \mathrm{~g} . \mathrm{L}^{-1} \mathrm{glu}-$ cose [24]. Similarly, ADH specific activity increased four folds in absence of sparging (Table 2) consistent with four-fold increase in the ethanol flux (Table 1). It has

Table 1 Fermentation data in continuous cultivations of C.saccharolyticus on glucose (5g. $\left.\mathrm{L}^{-1}\right)$ at steady states of different dilution rates, with and without $\mathrm{N}_{2}$ sparging.

\begin{tabular}{|c|c|c|c|}
\hline \multirow[t]{2}{*}{ Parameter } & \multicolumn{3}{|c|}{ Results obtained with and without $\mathrm{N}_{2}$ sparging at $D\left(\mathrm{~h}^{-1}\right)$ of: } \\
\hline & $\begin{array}{c}0.05 \\
\left(100 \mathrm{~mL} / \mathrm{min} \mathrm{N}_{2}\right)\end{array}$ & $\begin{array}{c}0.15 \\
\left(100 \mathrm{~mL} / \mathrm{min} \mathrm{N}_{2}\right)\end{array}$ & $\begin{array}{c}0.05 \\
\text { no stripping }\end{array}$ \\
\hline Biomass conc. (g/L) & $0.51 \pm 0.02$ & $0.61 \pm 0.05$ & $0.42 \pm 0.01$ \\
\hline Residual glucose conc. (mM) & $0.05 \pm 0.03$ & $3 \pm 2$ & $0.3 \pm 0.3$ \\
\hline$q_{\text {glucose }}(\mathrm{mmol} / \mathrm{g} / \mathrm{h})$ & $2.90 \pm 0.09$ & $6.2 \pm 0.4$ & $3.2 \pm 0.4$ \\
\hline$q_{\text {pyruvate }}(\mathrm{mmol} / \mathrm{g} / \mathrm{h})$ & $4.90 \pm 0.19$ & $9.55 \pm 0.03$ & $5.8 \pm 0.7$ \\
\hline$q_{\mathrm{H} 2}(\mathrm{mmol} / \mathrm{g} / \mathrm{h})$ & 10. $1 \pm 0.4$ & $18.0 \pm 0.0$ & $5.9 \pm 0.6$ \\
\hline \multicolumn{4}{|l|}{ Product yield (mol/mol) } \\
\hline $\mathrm{H}_{2}$ & $3.48 \pm 0.09$ & $2.9 \pm 0.2$ & $1.82 \pm 0.03$ \\
\hline Acetate & $1.61 \pm 0.03$ & $1.32 \pm 0.13$ & $0.83 \pm 0.02$ \\
\hline Lactate & $0.01 \pm 0.00$ & $0.01 \pm 0.01$ & $0.67 \pm 0.01$ \\
\hline Ethanol & $0.07 \pm 0.00$ & $0.20 \pm 0.03$ & $0.28 \pm 0.04$ \\
\hline Biomass (g/mol) & $17.3 \pm 0.5$ & $24.1 \pm 1.5$ & $16 \pm 2$ \\
\hline$Y_{\text {ATP }}$ (g cells/mol ATP) & $5.4 \pm 0.2$ & $9.1 \pm 0.3$ & $6.7 \pm 0.6$ \\
\hline Carbon recovery (\%) & $0.96 \pm 0.01$ & $0.93 \pm 0.04$ & $0.93 \pm 0.02$ \\
\hline Redox recovery (\%) & $0.98 \pm 0.01$ & $0.93 \pm 0.03$ & $0.97 \pm 0.02$ \\
\hline
\end{tabular}


Table 2 Enzyme levels (IU.(mg protein $\left.{ }^{-1}\right)$ ) of key catabolic redox-dependent enzymes at steady states at different dilution rates, i.e. GAPDH, ADH, LDH and estimated activity (\% of potential activity) of LDH (LDHv) under physiological conditions (Tables 3,4 ) based on previously described kinetic model [23], of $C$. saccharolyticus cultures in the presence and absence of $\mathbf{N}_{2}$ sparging. Presented data is average of one biological and at least three technical replicates at a linear range.

Enzyme Results obtained with and without $\mathrm{N}_{2}$ sparging at $D\left(\mathrm{~h}^{-1}\right)$ of:

\begin{tabular}{cccc}
\cline { 2 - 4 } & $\begin{array}{c}\mathbf{0 . 0 5} \\
\left(\mathbf{1 0 0} \mathbf{~ m L} / \mathbf{m i n ~} \mathbf{N}_{\mathbf{2}}\right)\end{array}$ & $\begin{array}{c}\mathbf{0 . 1 5} \\
\left.\mathbf{( 1 0 0} \mathbf{~} \mathbf{m} / \mathbf{m i n ~}_{\mathbf{2}}\right)\end{array}$ & $\begin{array}{c}\mathbf{0 . 0 5} \\
\text { no sparging }\end{array}$ \\
\hline GAPDH & 3.5 & 1.4 & 1.3 \\
ADH & 0.44 & 0.96 & 1.8 \\
LDH & 1.2 & 2.6 & 8.3 \\
LDHv & 10 & 25 & 100 \\
\hline
\end{tabular}

been shown previously that the levels of this enzyme in C. saccharolyticus increased three folds during batch growth at the onset of the stationary phase [24]. The levels of the GAPDH and ADH in C. saccharolyticus under $\mathrm{N}_{2}$ sparging were comparable to the measured levels of the corresponding enzymes in $\mathrm{Cl}$. cellulolyticum under equivalent conditions [32]. However, LDH activity was about three folds higher in sparged cultures of $\mathrm{Cl}$. cellulolyticum at the low dilution rate [32], which could be a consequence of the strong regulation of the enzyme [24].

\section{Inhibition of GAPDH by NADH}

To investigate the effect of increased dissolved hydrogen concentration on the glycolytic flux, the effect of NAD and NADH on GAPDH activity in C. saccharolyticus was investigated in vitro. Conversion of GAP and NAD by GAPDH followed Michaelis-Menten kinetics, with $K_{0.5}$ values of $1.5 \pm 0.3$ and $0.28 \pm 0.06 \mathrm{mM}$ for GAP and NAD, respectively. Fitting the kinetic model to the data (Eq. 6) showed that there is no interaction between NAD and GAP when binding to the enzyme. $\mathrm{NADH}$ inhibited the reaction in a competitive manner $\left(K_{\mathrm{NADH}}=0.03 \pm 0.01 \mathrm{mM}\right.$; Eq. 7$)$, based on Dixon and Cornish-Bowden plots (Figure 2A and 2B) as well as through model discrimination by comparative fitting different inhibition models to the data $\left(R^{2}=0.974\right.$ for the competitive model; data not shown). The activity of GAPDH appeared to follow Hill kinetics with respect to changes in NADH/NAD ratio (Figure 2C; $R^{2}$ $\left.=0.9817 ; K_{\mathrm{R}}=0.09 \pm 0.01 ; h=-0.8 \pm 0.1\right)$. Moreover, increase in the NADH/NAD ratio up to one, was unable to fully inhibit the enzyme (Figure 2C). Based on the estimated value for $K \mathrm{i}$ of NADH, GAPDH in $C$. saccharolyticus was more resistant to increased NADH levels than the GAPDH of most other related bacteria.
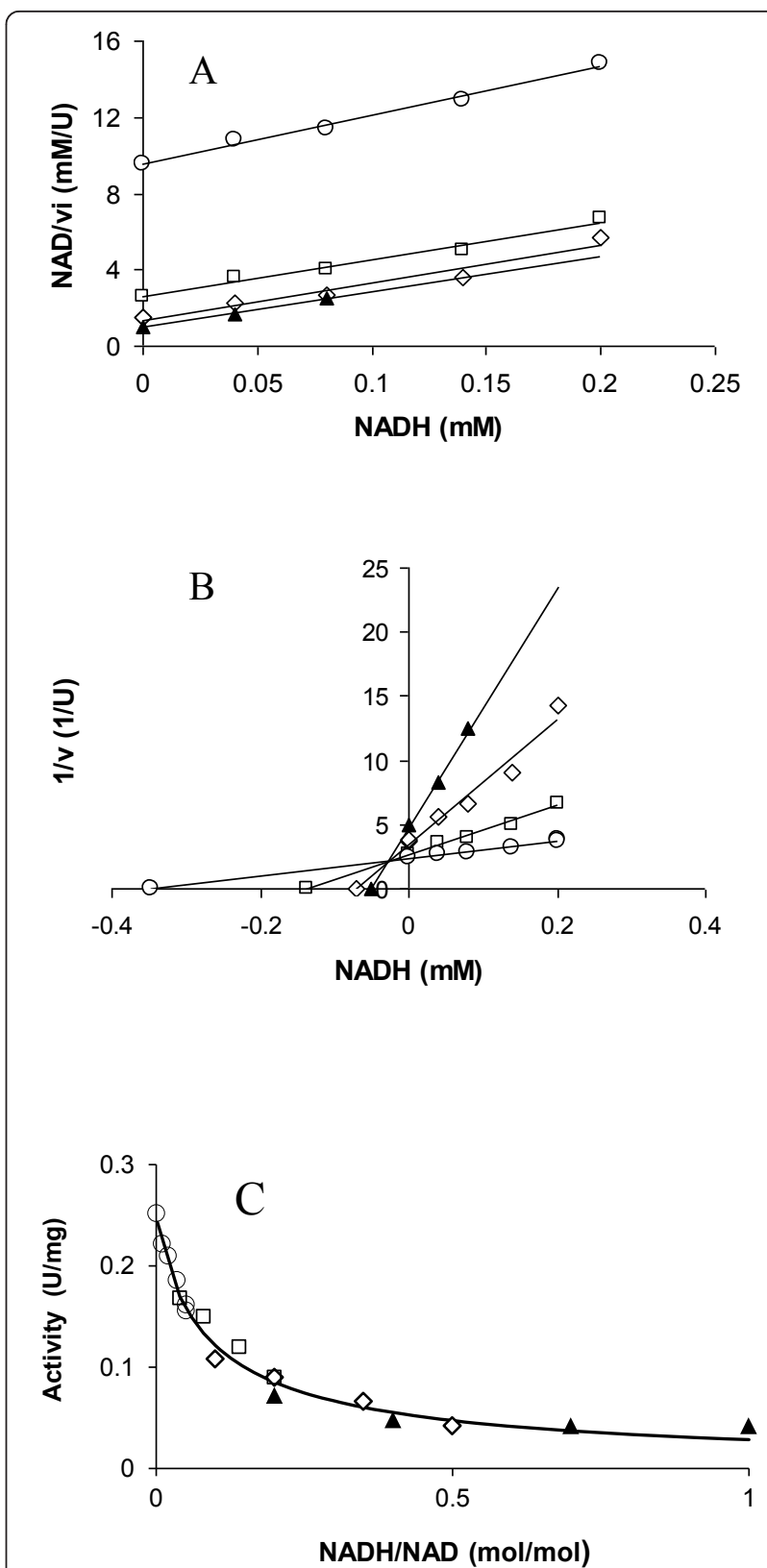

Figure 2 Inhibition of GAPDH of $C$. saccharolyticus by NADH. (A) Cornish-Bowden plot; (B) Dixon plot and (C) the effect of NADH/ NAD ratio on specific activity of GAPDH with four different NAD concentrations; $0.2 \mathrm{mM}(\mathbf{\Delta}), 0.4 \mathrm{mM}(\diamond), 1 \mathrm{mM}(\square)$ and $4 \mathrm{mM}(0)$.

The NADH concentration that causes $50 \%$ inhibition of the enzyme of C. saccharolyticus was $0.03 \mathrm{mM}$, as compared to $0.01 \mathrm{mM}$ for $T$. thermohydrosulfuricus (formerly known as Clostridium thermohydrosulfuricum; [35]) and $\mathrm{Cl}$. acetobutylicum [34]. However, the enzyme of $C$. saccharolyticus is less resistant to NADH inhibition than that of $\mathrm{Cl}$. cellulyticum [36], for which $50 \%$ inhibition was observed at $0.1 \mathrm{mM} \mathrm{NADH}$ (Figure $2 \mathrm{C}$ ). Consistently, the NADH/NAD ratio in the cells of 
Cl. cellulyticum is significantly higher than in C. saccharolyticus [24,37].

Finally, the activity of GAPDH was not found to be influenced by ATP, ADP or PPi over the physiological range of metabolite concentrations (1-10 mM).

\section{Redox metabolism and its effect on the glycolytic flux}

High $P_{\mathrm{H} 2}$ can potentially inhibit $\mathrm{H}_{2}$ formation through product inhibition of the hydrogenase-catalyzed NADH oxidation [38], which could lead to increased NADH/ NAD ratios [37]. To investigate whether this was the case for C. saccharolyticus in the absence of sparging, $\mathrm{NADH}$ and NAD levels were determined at steady state conditions with and without sparging (Table 3). Interestingly, the NADH/NAD ratio remained similar $(0.12$ $\mathrm{mol} / \mathrm{mol}$; Table 3 ) at which the GAPDH activity was decreased for about $50 \%$ by NADH inhibition (Figure $2 C)$. These results indicate that $C$. saccharolyticus sustains the NADH/NAD ratio at a homeostatic level as to support a high glycolytic flux. This could be achieved inside the cells by two mechanisms, i) by regulating the activity of GAPDH and/or ii) by redirecting pyruvate flux to more reduced products.

Under given conditions, the overall glycolytic flux can be measured as pyruvate flux. Hence, it could be argued that, glycolytic flux is a function of the activity of GAPDH $\left(\mathrm{q}_{\text {pyruvate }}=\mathrm{f}\left(\mathrm{v}_{\text {GAPDH }}\right)\right.$. The activity of GAPDH, in turn, is a function of NADH/NAD ratio $\left(\mathrm{v}_{\mathrm{GAPDH}}=\mathrm{f}\right.$ (NADH/NAD); Figure 2C; Figure 3). Consistently, a slight decrease in the NADH/NAD ratio appears to result in $94 \%$ higher pyruvate flux as a consequence of $9 \%$ increase in the GAPDH activity (at D $=0.15 \mathrm{~h}^{-1}$; Table 1, 2; Figure 2C).

At high $P_{H 2}, 53 \%$ of the pyruvate flux was redirected to lactate and ethanol (Table 1). This redirection is clearly illustrated by the estimated ratio of the NADH production flux over the NADH flux to reduced products ( $q_{\text {NADHProduced }} / q_{\text {NADH }}$ used $)$, which is eight folds lower at high $P_{\mathrm{H} 2}$ (Table 3 ). At this higher flux to reduced products, the NADH available for hydrogen formation is decreased ( 2.5 folds) as a strategy of the cell to maintain low NADH/NAD ratios at all the conditions,

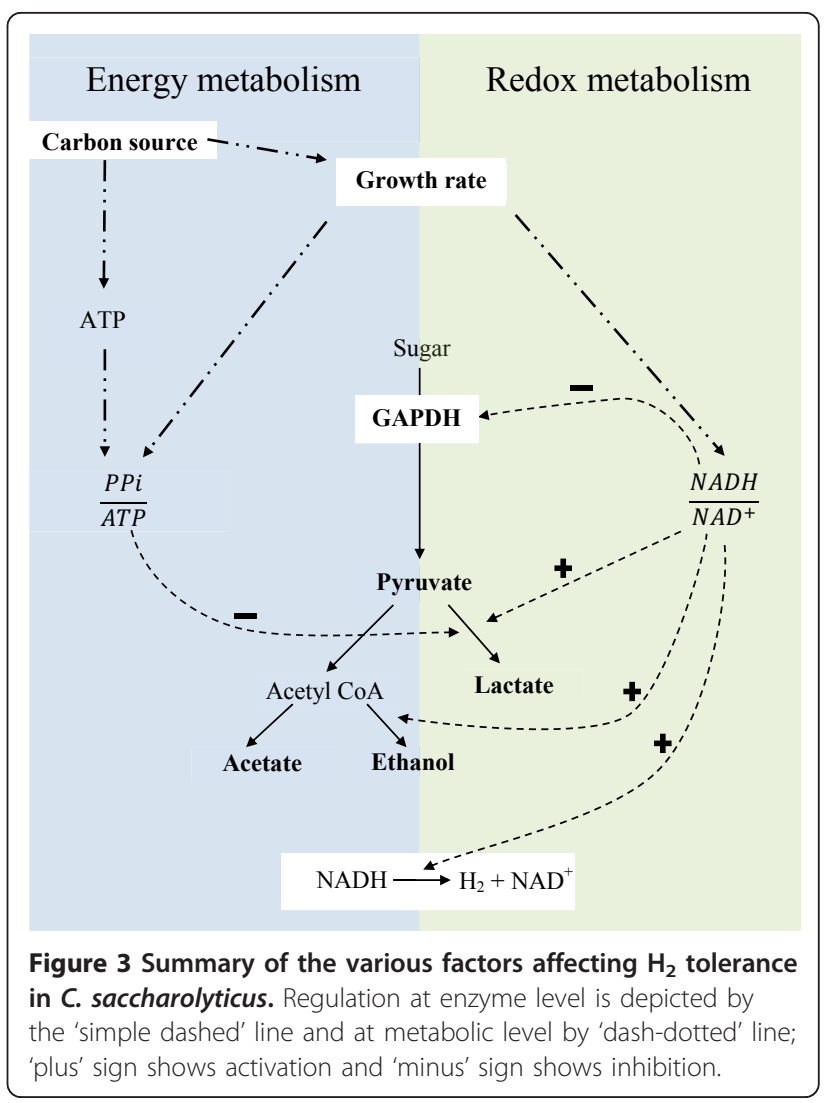

including where the elevated dissolved hydrogen concentration inhibits the NADH-dependent hydrogenase reaction. This inhibition of hydrogen formation is evaluated by thermodynamic analysis.

\section{Thermodynamic analysis}

The critical $P_{\mathrm{H} 2}$ is dependent on the NAD/NADH ratio and the temperature according to (Eq. 7, [39,40]):

$$
P_{\mathrm{H} 2}=\frac{[N A D(P) H]}{N A D(P)^{+}} e-\left[\frac{E^{\prime^{0}} N A D(P)^{+}-E^{0^{0}} H_{2}}{\frac{R T}{2 F}}\right]
$$

Table 3 Measured NADH/NAD ratios and NADH concentration and estimated redox fluxes at steady states of different dilution rates of C.saccharolyticus cultures in the presence and absence of $\mathbf{N}_{\mathbf{2}}$ sparging

\begin{tabular}{|c|c|c|c|}
\hline \multirow[t]{2}{*}{ Parameter } & \multicolumn{3}{|c|}{ Results obtained with and without $\mathrm{N}_{2}$ sparging at $D\left(\mathrm{~h}^{-1}\right)$ of: } \\
\hline & $\begin{array}{c}0.05 \\
\left(100 \mathrm{~mL} / \mathrm{min} \mathrm{N}_{2}\right)\end{array}$ & $\begin{array}{c}0.15 \\
\left(100 \mathrm{~mL} / \mathrm{min} \mathrm{N}_{2}\right) \\
\end{array}$ & $\begin{array}{c}0.05 \\
\text { no stripping } \\
\end{array}$ \\
\hline $\mathrm{NADH} / \mathrm{NAD}(\mathrm{mol} / \mathrm{mol})$ & $0.13 \pm 0.02$ & $0.10 \pm 0.00$ & $0.12 \pm 0.00$ \\
\hline$a_{\text {NADH }}$ produced $(\mathrm{mmol} / \mathrm{g} / \mathrm{h})$ & $4.90 \pm 0.2$ & $9.55 \pm 0.03$ & $5.8 \pm 0.7$ \\
\hline$q_{\text {NADH }}$ used $(\mathrm{mmol} / \mathrm{g} / \mathrm{h})$ & $0.44 \pm 0.03$ & $2.6 \pm 0.5$ & $4.0 \pm 0.7$ \\
\hline$a_{N A D H}$ produced $/ a_{N A D H}$ used $(\mathrm{mol} / \mathrm{mol})$ & 11 & 3.7 & 1.4 \\
\hline $\mathrm{NADH}$ available for $\mathrm{H}_{2}$ :ase $(\mathrm{mmol} / \mathrm{g} / \mathrm{h})$ & 4.5 & 7.0 & 1.8 \\
\hline
\end{tabular}


where $E^{\circ}$ is the midpoint reduction potential, $\mathrm{F}$ is the Faraday's constant, $R$ is the ideal gas constant and T is the absolute temperature (K).

Therefore, lower NADH/NAD ratios make the hydrogenase reaction more energetically favourable, which was confirmed experimentally by Veit et al [39]. Consistently, the ethanol-adapted $T$. thermohydrosulfuricus strain, which is more tolerant to $\mathrm{H}_{2}$ than the wild-type strain, possessed a GAPDH which could tolerate approximately twice the amount of NADH concentrations as the GAPDH of its wild-type variant [35].

At NADH/NAD ratios of $0.12 \mathrm{~mol} / \mathrm{mol}$ (Table 3 ) measured herein, the critical $P_{\mathrm{H} 2}$ for hydrogen production at $70^{\circ} \mathrm{C}$ should be $12 \mathrm{~Pa}$ in the headspace (Eq. 7) and thus $\mathrm{H}_{2}$-generation should not be possible to occur spontaneously at $67 \mathrm{kPa}$. Yet, $C$. saccharolyticus cultures were able to produce $\mathrm{H}_{2}$ at this high $P_{\mathrm{H} 2}$.

One way to circumvent this apparent contradiction could be via the substrate specificity of different hydrogenase enzymes. Based on sequence similarity, C. saccharolyticus possesses two distinct hydrogenases, one NADH-dependent Fe-only hydrogenase (Csac_18601864) and one ferredoxin (Fd)-dependent, membraneassociated NiFe-hydrogenase (Csac_1540-1545; [17]). Given that the redox potential of the Fd couple $\left(\mathrm{Fd}_{\text {red }} /\right.$ $\mathrm{Fd}_{\mathrm{ox}}$ ) is close to that of $\mathrm{H}_{2}$ (approx. $-400 \mathrm{mV}$, albeit depending on the involved enzyme [41]), the reaction is energetically favourable even at $P_{\mathrm{H} 2}$ close to $39 \mathrm{kPa}$. Therefore, it is possible that the NiFe hydrogenase-catalyzed reaction in $C$. saccharolyticus is still functioning even at elevated dissolved $\mathrm{H}_{2}$ concentrations. It is noteworthy that the NADH-dependent Fe-only hydrogenase in $T$. tengcongensis was down regulated at high $P_{\mathrm{H} 2}$, while the Fd-dependent hydrogenases were constitutively expressed, irrespective of the $P_{\mathrm{H} 2}$ [42].

An alternative explanation can be proposed related to the finding of Schut and Adams [43], concerning the Fe-only hydrogenase in T. maritima using NADH and $\mathrm{Fd}_{\text {red }}$ simultaneously in a bifurcating manner. This novel bifurcating hydrogenase could therefore catalyze the unfavourable oxidation of NADH to $\mathrm{H}_{2}$ by using the exothermic oxidation of $\mathrm{Fd}_{\text {red }}$ to drive the reaction. It is noteworthy that the sequence of the Fe-only hydrogenase in C. saccharolyticus (Csac_1860-1864) is similar to the bifurcating hydrogenase in T. maritima (TM1424TM1426 [43]). However, it remains to be investigated whether this hydrogenase enzyme in C. saccharolyticus possesses a bifurcating function.

\section{Energy metabolism and its impact on lactate and hydrogen formation}

The total ATP and PPi pool in C. saccharolyticus increased with the growth rate (Table 4), which is in contrast to what was reported for ATP for C. cellulolyticum [32]. In addition, increased levels of both ATP and PPi were observed in the absence of sparging (Table 4) probably due to cell lysis caused by high dissolved $\mathrm{CO}_{2}$ concentrations as ATP and PPi were released in the culture broth $[15,31]$. The latter was confirmed by lower biomass concentration (Table 1). The levels of ATP and PPi are in the same range as under stationary growth of $C$. saccharolyticus [24] and the PPi/ATP ratios are low in all conditions (Table 4). This suggests that LDH should be present in an active configuration during all conditions. However, due to the low NADH/NAD ratio of $0.1 \mathrm{~mol} /$ mol, the sensitivity of $\mathrm{LDH}$ to changes in $\mathrm{PPi} / \mathrm{ATP}$ ratio is stronger [24]. In addition, the level of $\mathrm{LDH}$ depends on the cultivation condition (Table 2). Consequently, the slightly higher PPi/ATP ratio reduces the estimated activity of LDH 10 and 2.5 folds at low $D$ and sparged conditions compared to the non-sparged and high $D$ condition, respectively (Table 2 , LDHv), partly explaining the significantly lower lactate yields in these conditions. However, the overall glycolytic and shifts in by-product formation is complex and merits more in depth studies. In addition, there is a competition for pyruvate at the pyruvate node (Table 1). Therefore, LDH kinetics alone could not explain the insignificant amount of lactate formed at higher $D\left(0.15 \mathrm{~h}^{-1}\right)$ even at higher measured LDH activity in this condition (Table 1 and 4 ).

\section{Effect of the carbon source on $\mathrm{H}_{2}$ tolerance}

The $\mathrm{H}_{2}$ tolerance in C. saccharolyticus is not only dependent on the growth phase of the organism (Figure

Table 4 ATP and PPi levels at steady states of different dilution rates of C.saccharolyticus cultures in the presence and absence of $\mathrm{N}_{2}$ sparging

\begin{tabular}{|c|c|c|c|}
\hline \multirow[t]{2}{*}{ Parameter } & \multicolumn{3}{|c|}{ Results obtained with or without stripping and at $D\left(h^{-1}\right)$ of: } \\
\hline & $\begin{array}{c}0.05 \\
\left(100 \mathrm{~mL} / \mathrm{min} \mathrm{N}_{2}\right)\end{array}$ & $\begin{array}{c}0.15 \\
\left(100 \mathrm{~mL} / \mathrm{min} \mathrm{N}_{2}\right)\end{array}$ & $\begin{array}{c}0.05 \\
\text { no stripping } \\
\end{array}$ \\
\hline ATP $\mathrm{mM}$ & $0.67 \pm 0.07$ & $0.80 \pm 0.06$ & $2.0 \pm 0.2$ \\
\hline ATP $\mu$ moles/g of cells & $3.06 \pm 0.32$ & $3.66 \pm 0.26$ & $8.95 \pm 0.91$ \\
\hline PPi mM & $0.92 \pm 0.05$ & $0.81 \pm 0.07$ & $2.1 \pm 0.4$ \\
\hline PPi $\mu$ moles/g of cells & $4.20 \pm 0.22$ & $3.69 \pm 0.34$ & $9.62 \pm 1.69$ \\
\hline PPi/ATP & 1.37 & 1.01 & 1.05 \\
\hline
\end{tabular}


1). The results obtained in this study indicated that the critical $P_{\mathrm{H} 2}$ for initiating lactate formation of $C$. saccharolyticus when grown on glucose was significantly higher than that of previously reported when the organism was grown on sucrose [23]. This led us to investigate whether various carbon sources would allow $C$. saccharolyticus to possess different $\mathrm{H}_{2}$ tolerances in an experimental set-up similar to that used by van Niel et al [23]. The fermentations were carried out in batch mode and the gas outlet of the bioreactor was closed at the beginning of the lag phase, leading to a build-up of the total pressure in the vessel due to accumulation of $\mathrm{H}_{2}$ and $\mathrm{CO}_{2}$. Indeed, the acetate and lactate fluxes were considerably influenced by the carbon source. For instance, the acetate/lactate ratio was 6 in the experiments on xylose, which can be compared to the significantly lower acetate/lactate ratio of 0.26 previously observed on sucrose [23]. The acetate and the lactate yield were 1.2 and 0.21 $\mathrm{mol} / \mathrm{mol} \mathrm{C6}$, respectively on xylose. In addition, lactate formation remained low in cultures on xylose, during the entire time span and acetate production still continued at $P_{\mathrm{H} 2}$ up to $60 \mathrm{kPa}$ (data not shown), while lactate was formed on sucrose when $\mathrm{H}_{2}$ accumulated beyond 10-20 kPa [23]. Every mol of lactate formed deprives the cells not only of a mol of $\mathrm{H}_{2}$ but also from obtaining an extra ATP. This is in accordance with previous work showing how the glycolytic flux is significantly increased when xylose is used as carbon source compared to that of sucrose [44]. High throughput technologies can be used to investigate this further in the future. Thus, the observed variability in the extent and sensitivity of lactate formation is also related to the energy metabolism of the cells that may vary with each carbon source (Figure 3 ; [11]).

\section{Conclusions}

C. saccharolyticus has the attractive property of producing high $\mathrm{H}_{2}$ yields under ideal conditions. When the $P_{\mathrm{H} 2}$ rises it has the ability to maintain glycolytic flux by regulating GAPDH. Required GAPDH activity is attained by keeping the NADH/NAD ratio relatively low through redistributing its metabolism towards more reduced end products, including lactate and ethanol. The results herein reveal that these redistributions are not solely dependent on the $P_{\mathrm{H} 2}$, but also on the growth state of the organism and the carbon source fermented. Although ethanol is produced, lactate remains the main alternative for C. saccharolyticus for reoxidizing NADH. For an economically attractive industrial application of C. saccharolyticus, hydrogen yields need to be kept maximized, for which metabolic shift to lactate should be kept at bay. In addition, $\mathrm{H}_{2}$ production should be achieved preferably without the need for sparging gas to prevent central costs for the gas-upgrading process [45].
A critical $P_{\mathrm{H} 2}$ should be set so as not to adversely affect the growth rate or biomass yield of the organism or to enhance lactate formation. This should be combined with a careful selection of the feedstock, based on the type of substrates, and operating at adequately low osmotic pressures [15]. Thus, according to our results, a xylose-rich feedstock is preferred over a sucrose-rich one, since the latter enforces an earlier effect of $P_{\mathrm{H} 2}$ on growth and lactate formation than the former. If $\mathrm{H}_{2}$ production is possible on a xylose-rich lignocellulosic feedstock and accomplished at high yields at high $P_{\mathrm{H} 2}$, it is definitely a critical step further towards a cost-effective biohydrogen process.

\section{Abbreviations}

$D$ : dilution rate; $h^{-1}$; $q_{\text {acetate }}$ specific formation/consumption rate:mmol $(\mathrm{gCDW})^{-1} \mathrm{~h}^{-1} ; q_{\text {ethanol: }}$ specific formation rate of ethanol; mmol $(\mathrm{gCDW})^{-1} \mathrm{~h}^{-1}$ qlactate: specific formation rate of lactate; $\mathrm{mmol}(\mathrm{gCDW})^{-1} \mathrm{~h}^{-1} ; q_{\mathrm{NADH}}$ : produced specific formation rate of $\mathrm{NADH} ; \mathrm{mmol}(\mathrm{gCDW})^{-1} \mathrm{~h}^{-1} ; q_{\mathrm{NADH}}$ : used specific formation rate of $\mathrm{NADH}$ used for lactate and ethanol; $\mathrm{mmol}$ (gCDW) ${ }^{1} \mathrm{~h}^{-1} ; q_{\text {glucose: }}$ specific consumption rate of glucose; mmol (gCDW $)^{-1} \mathrm{~h}^{-1}$; $q_{\text {pyruvate: }}$ specific formation rate of intracellular pyruvate; $\mathrm{mmol}_{(\mathrm{gCDW})^{-1}} \mathrm{~h}^{-1}$ $Y_{X / A T P}$ : energetic biomass yield; gCDW molATP-1; $\mu$ : specific growth rate; $h^{-1}$; $P_{\mathrm{H} 2}$ : partial $\mathrm{H}_{2}$ pressure; $\mathrm{kPa} ; K_{\mathrm{i}}$ : inhibition constant

\section{Acknowledgements}

S.S.P. acknowledges support from the Swedish Energy Agency (Energimyndigheten; 31090-1). Mattias Ljunggren is acknowledged for his assistance with batch experiments and Dr. Ahmad Zeidan for fruitful discussions on experimental setup as well as for critically reviewing the article. This work was financially supported by the Commission of European Communities, Sixth Framework Program, Priority 6, Sustainable Energy Systems (019825 HYVOLUTION).

\section{Authors' contributions}

KW planned the content of the article. KW also planned and preformed the batch experiments and was involved in the planning of the continuous cultures experiments and enzyme kinetics experiments. SP planned and performed the continuous cultures, enzyme kinetics and metabolite analysis. $\mathrm{KW}$ and SP both wrote a part of the paper. EvN was involved in the planning of the experiments and supervised the processes. EvN also critically reviewed the text. All authors have read and approved the manuscript.

\section{Competing interests}

The authors declare that they have no competing interests.

Received: 23 October 2011 Accepted: 21 December 2011 Published: 21 December 2011

\section{References}

1. Hallenbeck PC, Ghosh D: Advances in fermentative biohydrogen production: the way forward? Trends Biotechnol 2009, 27:287-297.

2. Nandi R, Sengupta S: Microbial production of hydrogen: An overview. Critical Reviews in Microbiology 1998, 24:61-84.

3. Das D, Veziroglu TN: Hydrogen production by biological processes: a survey of literature. International Journal of Hydrogen Energy 2001, 26:13-28.

4. Kleerebezem R, van Loosdrecht MCM: Mixed culture biotechnology for bioenergy production. Curr Opin Biotechnol 2007, 18:207-212.

5. Kengen SWM, Goorissen HP, Verhaart M, van Niel EWJ, Claassen PAM, Stams AJM: Biological hydrogen production by anaerobic microorganisms. In Biofuels. Edited by: Soetaert W, Vandamme EJ. Chichester: John Wiley 2009:197-221.

6. Thauer RK, Jungermann K, Decker K: Energy conservation in chemotrophic anaerobic bacteria. Bacteriol Rev 1977, 41:100-180.

7. Stams AJM: Metabolic interactions between anaerobic bacteria in methanogenic environments. Antonie Van Leeuwenhoek 1994, 66:271-294 
8. Adams MWW: The metabolism of hydrogen by extremely thermophilic, sulfur-dependent bacteria. FEMS Microbiol Rev 1990, 75:219-237.

9. de Vrije T, Mars AE, Budde MA, Lai MH, Dijkema C, de Waard P, Claassen PAM: Glycolytic pathway and hydrogen yield studies of the extreme thermophile Caldicellulosiruptor saccharolyticus. Appl Microbiol Biotechnol 2007, 74:1358-1367.

10. Schröder $C$, Selig M, Schönheit P: Glucose fermentation to acetate, $\mathrm{CO}_{2}$ and $\mathrm{H}_{2}$ in the anaerobic hyperthermophilic eubacterium Thermotoga maritima - Involvement of the Embden-Meyerhof Pathway. Arch Microbiol $1994,161: 460-470$

11. Zeidan AA, van Niel EWJ: A quantitative analysis of hydrogen production efficiency of the extreme thermophile Caldicellulosiruptor owensensis OLT. Int J Hydrogen Energy 2010, 35:1128-1137.

12. Kraemer JT, Bagley DM: Improving the yield from fermentative hydrogen production. Biotechnol Lett 2007, 29:685-695.

13. van Groenestijn JW, Hazewinkel JHO, Nienoord M, Bussmann PJT: Energy aspects of biological hydrogen production in high rate bioreactors operated in the thermophilic temperature range. Int J Hydrogen Energy 2002, 27:1141-1147.

14. Kim DH, Han SK, Kim SH, Shin HS: Effect of gas sparging on continuous fermentative hydrogen production. International Journal of Hydrogen Energy 2006, 31:2158-2169.

15. Willquist $\mathrm{K}$, Claasen PAM, van Niel EWJ: Evaluation of the influence of $\mathrm{CO}_{2}$ on hydrogen production in Caldicellulosiruptor saccharolyticus. Int J Hydrogen Energy 2009, 34:4718-4726.

16. van Niel EWJ, Budde MAW, de Haas GG, van der Wal FJ, Claassen PAM, Stams AJM: Distinctive properties of high hydrogen producing extreme thermophiles, Caldicellulosiruptor saccharolyticus and Thermotoga elfii. Int $J$ Hydrogen Energy 2002, 27:1391-1398.

17. van de Werken HJG, Verhaart MRA, VanFossen AL, Willquist $\mathrm{K}$, Lewis $\mathrm{DL}$, Nichols JD, Goorissen HP, Mongodin EF, Nelson KE, van Niel EWJ, et al: Hydrogenomics of the Extremely Thermophilic Bacterium Caldicellulosiruptor saccharolyticus. Appl Environ Microbiol 2008 74:6720-6729.

18. Van Fossen AL, Verhaart MRA, Kengen SWM, Kelly RM: Carbohydrate utilization patterns for the extremely thermophilic bacterium Caldicellulosiruptor saccharolyticus reveal broad growth substrate preferences. Appl Environ Microbiol 2009, 75:7718-7724.

19. Kadar Z, De Vrije T, Budde MA, Szengyel Z, Reczey K, Claassen PAM: Hydrogen production from paper sludge hydrolysate. Appl Biochem Biotechnol 2003, 105-108:557-566.

20. de Vrije T, Bakker RR, Budde MAW, Lai MH, Mars AE, Claassen PAM: Efficient hydrogen production from the lignocellulosic energy crop Miscanthus by the extreme thermophilic bacteria Caldicellulosiruptor saccharolyticus and Thermotoga neapolitana. Biotech Biofuels 2009, 2:12

21. Hong MR, Kim YS, Park CS, Lee JK, Oh DK: Characterization of a recombinant beta-glucosidase from the thermophilic bacterium Caldicellulosiruptor saccharolyticus. J Biosci Bioeng 2009, 108:36-40.

22. Ivanovaa G, Rakhely G, Kovacs KL: Hydrogen production from biopolymers by Caldicellulosiruptor saccharolyticus and stabilization of the system by immobilization. Int J Hydrogen Energy 2008, 33:6953-6961.

23. van Niel EWJ, Claassen PAM, Stams AJM: Substrate and product inhibition of hydrogen production by the extreme thermophile, Caldicellulosiruptor saccharolyticus. Biotechnol Bioeng 2003, 81:255-262.

24. Willquist $\mathrm{K}$, van Niel EWJ: Lactate formation in Caldicellulosiruptor saccharolyticus is regulated by the energy carriers pyrophosphate and ATP. Metab Eng 2010, 12:282-290.

25. Bernofsky C, Swan M: An improved cycling assay for nicotinamide adenine dinucleotide. Anal Biochem 1973, 53:452-458.

26. Bielen AAM, Willquist K, Engman J, van der Oost J, van Niel EWJ, Kengen SWM: Pyrophosphate as a central energy carrier in the hydrogen-producing extremely thermophilic Caldicellulosiruptor saccharolyticus. Fems Microbiology Letters 2010, 307:48-54.

27. Hassibi A, Contag C, Vlad MO, Hafezi M, Lee TH, Davis RW, Pourmand N: Bioluminescence regenerative cycle (BRC) system: theoretical considerations for nucleic acid quantification assays. Biophys Chem 2005, 116:175-185.

28. Guedon E, Payot S, Desvaux M, Petitdemange H: Carbon and Electron Flow in Clostridium cellulolyticum Grown in Chemostat Culture on Synthetic Medium. J Bacteriol 1999, 181:3262-3269.
29. CRC Handbook of Chemistry and Physics. Edited by: Lide DR. Gaithersburg, MD: CRC Press; , 92 2009:

30. Leskovac V: Comprehensive enzyme kinetics New York: Kluwer Academic/ Plenum Pub; 2003

31. Ljunggren $M$, Willquist $K$, Zacchi $G$, van Niel E: A kinetic model for quantitative evaluation of the effect of $\mathrm{H}_{2}$ and osmolarity on hydrogen production by Caldicellulosiruptor saccharolyticus. Biotechnology for Biofuels 2011, 4:31.

32. Guedon E, Payot S, Desvaux M, Petitdemange H: Relationships between cellobiose catabolism, enzyme levels, and metabolic intermediates in Clostridium cellulolyticum grown in a synthetic medium. Biotechnology and Bioengineering 2000, 67:327-335.

33. Hild HM, Stuckey DC, Leak DJ: Effect of nutrient limitation on product formation during continuous fermentation of xylose with Thermoanaerobacter ethanolicus JW200 Fe(7). Appl Microbiol Biotechnol 2003, 60:679-686.

34. Girbal L, Soucaille P: Regulation of Clostridium acetobutylicum metabolism as revealed by mixed-substrate steady-state continuous cultures - role of NADH/NAD ratio and ATP Pool. J Bacteriol 1994, 176:6433-6438.

35. Lovitt RW, Shen GJ, Zeikus JG: Ethanol production by thermophilic bacteria - biochemical basis for ethanol and hydrogen tolerance in Clostridium thermohydrosulfuricum. J Bacteriol 1988, 170:2809-2815.

36. Payot S, Guedon E, Cailliez C, Gelhaye E, Petitdemange H: Metabolism of cellobiose by Clostridium cellulolyticum growing in continuous culture: evidence for decreased NADH reoxidation as a factor limiting growth. Microbiology 1998, 144:375-384

37. Payot $\mathrm{S}$, Guedon $\mathrm{E}$, Gelhaye $\mathrm{E}$, Petitdemange $\mathrm{H}$ : Induction of lactate production associated with a decrease in NADH cell content enables growth resumption of Clostridium cellulolyticum in batch cultures on cellobiose. Research in Microbiology 1999, 150:465-473.

38. Morgan H, Ronimus R: Pyrophosphate-dependent phosphofructokinase in thermophilic and non-thermophilic microorganisms London: Taylor and Francis; 1998.

39. Velt A, Kallm AM, Mizutani T, Jones PR: Constructing and testing the thermodynamic limits of synthetic $\mathrm{NAD}(\mathrm{P}) \mathrm{H}: \mathrm{H}_{2}$ pathways. Microbiol Biotechnol 2008, 1:382-394.

40. Willquist K, Zeidan A, van Niel E: Physiological characteristics of the extreme thermophile Caldicellulosiruptor saccharolyticus: an efficient hydrogen cell factory. Microbial Cell Factories 2010, 9:89.

41. Smith ET, Blamey JM, Zhou ZH, Adams MWW: A variable-temperature direct electrochemical study of metalloproteins from hyperthermophilic microorganisms involved in hydrogen production from pyruvate. Biochemistry 1995, 34:7161-7169.

42. Soboh B, Linder D, Hedderich R: A multisubunit membrane-bound [NiFe] hydrogenase and an $\mathrm{NADH}$-dependent Fe-only hydrogenase in the fermenting bacterium Thermoanaerobacter tengcongensis. Microbiology 2004, 150:2451-2463.

43. Schut GJ, Adams MWW: The Iron-Hydrogenase of Thermotoga maritima Utilizes Ferredoxin and NADH Synergistically: A New Perspective on Anaerobic Hydrogen Production. J Bacterio/ 2009, JB.01582-01508.

44. Kostesha N, Willquist K, Emneus J, van Niel E: Probing the redox metabolism in the strictly anaerobic, extremely thermophilic, hydrogenproducing Caldicellulosiruptor saccharolyticus using amperometry. Extremophiles 2011, 15:77-87.

45. Ljunggren M, Zacchi G: Techno-economic evaluation of a two-step biological process for hydrogen production. Biotechnol Prog 2010, 26:496-504.

\section{doi:10.1186/1475-2859-10-111}

Cite this article as: Willquist et al:: Reassessment of hydrogen tolerance in Caldicellulosiruptor saccharolyticus. Microbial Cell Factories 2011 10:111 